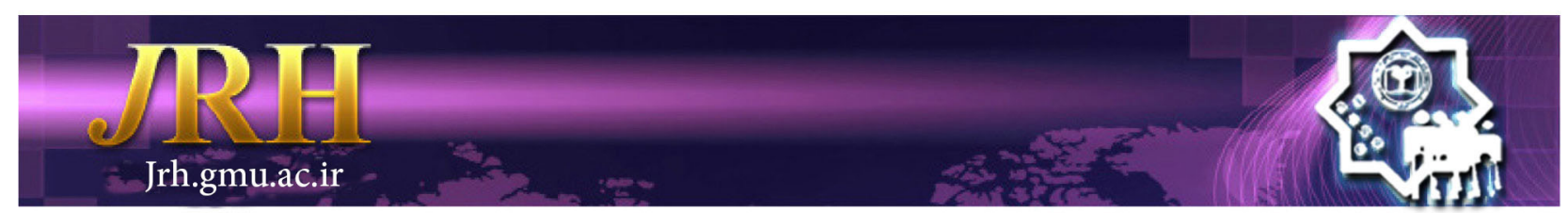

\title{
Mediating role of resilience and tendency to addiction regarding the effect of gender on substance use \\ Hashem Jebraeili ${ }^{1}$, Mojtaba Habibi ${ }^{2}$, Alieh Nazemi ${ }^{2}$
}

\author{
Journal of Research \& Health \\ Social Development \& Health Promotion \\ Research Center \\ Vol. 9, No.3, May \& Jun 2019 \\ Pages: 236- 245 \\ DOI: $10.29252 /$ jrh.9.3.236 \\ Original Article
}

1. Correspondence to: Department of Psychology, School of Social and Educational Sciences, Razi University, Kermanshah, Iran Email: h.jebraeili@yahoo.com

2. Department of Health Psychology, School of Behavioral Sciences and Mental Health, University of Medical Sciences, Tehran, Iran 3. Young Researchers and Elite Club, Ardebil Branch, Islamic Azad University, Ardebil, Iran

Received: 14 Jul 2016

Accepted: 2 Jul 2018

How to cite this article: Jebraeili H, Habibi M, Nazemi A. Mediating role of resilience and tendency to addiction regarding the effect of gender on substance use. $J$ Research \& Health2019; 9(3): 236- 245.

\begin{abstract}
Resilience as flexible response to the pressures of daily life acts differently based on gender. Therefore, it can have mediating role in relation to the effect of gender on substance use. This study aimed to examine the mediating role of resilience and tendency to addiction regarding the effect of gender on substance use. 300 university students (124 males and 176 females) were chosen by the convenience sampling method and they were evaluated by the resilience scale, the tendency to addiction questionnaire, and a researcher-made questionnaire about substance use. The results showed that there was a significant positive relationship between the tendency to addiction and substance use; there was a significant negative correlation between the tendency to addiction and resilience; there was a negative relationship between male gender and resilience; and there was a significant positive relationship between male gender and tendency to addiction. In addition, the proposed model fitted the data. Resilience has an important role in the prevention of substance use and those with high scores on resilience, despite a tendency to addiction, are less prone to substance use because of the ability to deal with difficult situations and flexible response to the pressures of daily life.
\end{abstract}

Keywords: Addiction, Resilience, Sex differences, Substance use

\section{Introduction}

Substance use and abuse are one of the most important problems that the society are facing with today. Every year in different countries, governments spend millions of dollars to fight with the drug or treat persons that are dependent on the substance. Statistics show that despite spending a lot of money, not only addiction has not decreased, but also the rate of drug use has increased significantly in recent decades among different communities, especially among teenagers and young adults [1].

Youth and adolescents that are dealing with the drug are involved in issues such as theft, violence, school failure, thinking without organization, reduced psychosocial adjustment, reduced problem-solving skills, and the increased degree of social isolation and depression [2]. Substance use increases the risk of illness and mortality and is associated with serious social consequences 
[3]. Smoking is a prevalent cause of disability and death in the world and it increases the risk of cancer, cardiovascular diseases, and respiratory and other health problems [4]. The consumption of other drugs, especially illegal drugs, has consequences like a conflict with the law and punishment in addition to damages to the consumer and the impact on health care [5]. Personal and social costs of substance use highlight the need for studying factors related to such behavior. Examination of factors associated with substance use and addiction has shown that gender is one of the most important predictors of smoking and substance use [6]. Evidence suggests that the biological sex and gender roles affect drug consumption and abuse [7]. Studies show that men consume all kinds of substances, including alcohol, tobacco, marijuana, cocaine, methamphetamine, prescription stimulants, heroin, and painkillers, more than women. The greatest difference between men and women is related to the amount of substance abuse. Men report abuse or dependence on alcohol, marijuana, narcotics, or stimulants two to three times more than women do. However, differences between men and women in taking painkillers or prescriptive stimulants are less and women approximately have reported the same amount of the consumption of these products [8].

Although men use alcohol more than women do and they constitute a considerable ratio of the consumption of alcohol in the society [9] and in comparison with women, they are more likely to be alcohol dependent [10], the degree of alcohol dependence is equal $[11,12]$. In fact, the gender difference in substance and alcohol use is not as obvious as it seems [7] and some researchers believe that the gender difference in drug and alcohol use is much exaggerated [13]. Perhaps one of the factors that cause this disparity is gender differences in the tendency to addiction [6]. Although evidence suggests that men abuse drugs more than women do [8], studies show that the women that have a tendency to addiction consume substance more than men and it is true about alcohol and other drugs use and even gambling. In other words, between men and women who tend to addiction, women consume drugs more intensively than men consume and more quickly are dragged into drug addiction [14,15].

Another factor that may play a mediating role in the relationship between gender and substance use is resilience that is one of the most important predictors of smoking and substance use [16]. Resilience as a process is considered as an ability or outcome of successful adaptation to the environment, despite the risks and threats, and it enables persons to acquire skills necessary for leaving behind the problems; even in very adverse and hard conditions, they cope with the challenges of the life and the stressful conditions [17] and they are less prone to destructive behaviors such as substance use $[18,19]$.

The term resilience as a component of personality in the late twentieth century was introduced into the psychological research based on excellent research in the field of control and direct influence on cognitive processes [20]. Initial theories about resilience emphasized the traits associated with positive outcomes in the face of adversity and tribulations of the life. The studies further showed that outer protective factors such as schools and efficient and supportive relationships with adults are also helpful in increasing resilience [21]. Current theories considered resilience as a multi-dimensional construction consisting of nature variables, such as temperament and character, along with specific skills, such as problem-solving skills [22].

In earlier studies, it was thought that resilience was the feature of wonderful people. However, recent research has shown that resilience despite gender differences $[23,24]$ is not the monopoly of great people and it has been observed in different people and at different levels of development, including childhood, adolescence, and adulthood [22]. The results indicate that the high levels of resilience help a person to use emotions and positive affections to leave behind bad 
experiences and back to good condition by increasing the levels of positive emotions and strengthening self-esteem and overcoming negative experiences [25].

Many researchers have reported a significant negative relationship between resilience and psychological problems [26]; they suggest these structures can play a mediating role between mental health and many other variables and by promoting resilience, a person can have resistance against stress and anxiety and overcome the factors that cause the creation of many psychological problems [27]. Friborg and et al. [28] showed that resilience not only can increase the ability to influence in alarming situations but also can lead the individual to flexibility in crisis and sensitive situations. Vincent [29] believes that resilience causes learning of behavioral and cognitive skills to mastering stressful situations, especially in interpersonal relations.

Studies have shown that resilience plays a protective role against substance use [18]. The results showed that people with high resilience have better health, higher self-esteem, and social support and they are less prone to substance abuse [30]. High resilience has a relationship with less consumption and less dependent on nicotine cigarettes [31] and higher scores of resilience are associated with days without smoking in the smoking cessation program [32]. In addition, there is a significant negative relationship between the resilience and tendency to addiction [16,33] and membership in an addiction group can be predicted through the low score of resilience [34].

Resilience itself is affected by gender and evidence suggests that women show different reactions in comparison with men in stressful situations and the resilience of people is different based on gender [23]. In addition, gender-based theories have shown that regardless of the culture in which people live, the inner ability, coping mechanism, and social support received by individuals are different based on gender that it not only leads to varying degrees of resilience in men and women [24] but also can mediate gender differences in Substance use [7]. According to what was said and the importance of factors influencing drug use among young people, the role of gender in this regard, and the significance of identifying variables with mediating roles, this study was carried out with the aim of investigating the mediating role of resilience and tendency to addiction in relation to the effect of gender on substance use (Figure 1).

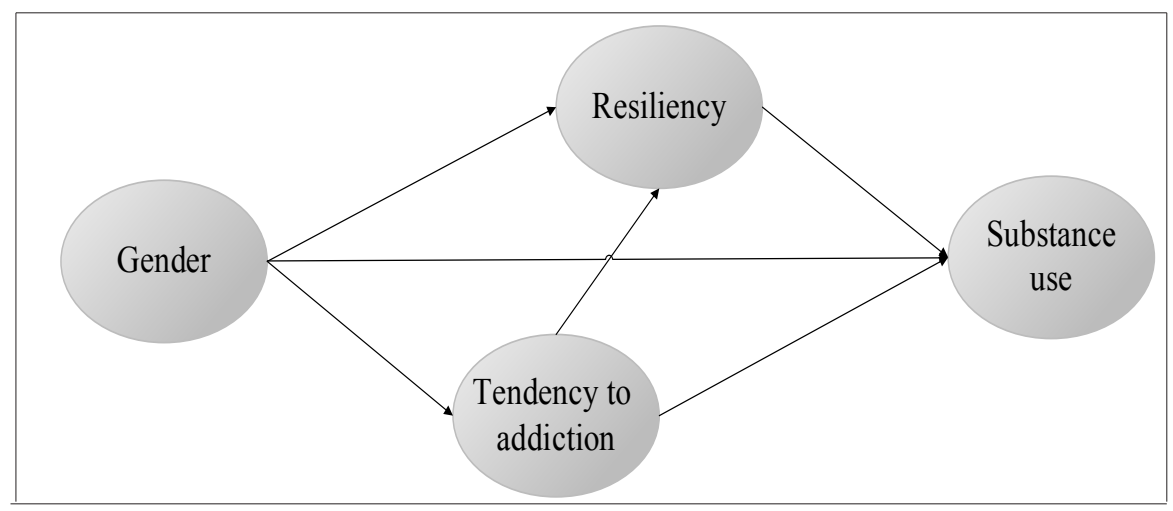

Figure 1 The theoretical framework of this study

\section{Method}

The present research utilized a correlational study. The study population consisted of all students studying in the academic year 20152016 at the university of Kharazmi, Karaj, Iran $(\mathrm{N}=10,000)$. The Cochran's formula with an error level of 5 percent was used to determine the sample size as 370 participants according to the size of the population. However, due to the possibility of drop-out, incomplete questionnaires, outlier values, data from 300 participants were used in the final analysis. The convenience sampling method was used 
for data gathering and the collected data were analyzed using Pearson and point-biserial correlation tests and the method of structural equation modeling in SPSS-22 and Structural Equation Modeling Software (EQS). Since the study was not a clinical trial in design, obtaining approval from the Ethics Committee was not necessary. However, in order to comply with the ethical issues and providing a secure environment for the participants, if students did not wish to complete a questionnaire, they could freely refuse to participate in the research. Furthermore, things such as "your answers will be used as a group in one study", "there is no need to mention names," and "there is no correct answer and whatever you believe is appreciated," were explained to the participants.

The tools of this study were conner \& davidson resilience scale, addiction tendency questionnaire, and a researcher-made questionnaire about substance use. Conner \& davidson have provided a questionnaire by reviewing the research resources in the field of resilience [35]. Evaluation of the psychometric properties of this scale was conducted in six groups consisting of a general population, those admitted to the primary care, psychiatric outpatients, patients with generalized anxiety disorder, and two groups of patients with post-traumatic stress disorders. The scale producers believe that this questionnaire is well able to separate the nonresilient and resilient individuals in clinical and non-clinical groups and it can be used in research and clinical situations.

The questionnaire has 25 questions scored on a 5 -point Likert scale from 0 to 4 . The maximum score for every participants is 100 and the minimum score is zero in this questionnaire. The cut-off point for the general population is 80.4 and in patients with post-traumatic stress disorder, it is 47.8 ; the higher score indicates greater resilience. The reliability of connor and davidson questionnaire has been reported as 0.85 using Cronbach's alpha in Ahmadi and Sharifi Daramadi research [36].

The Addiction Tendency scale was made by Weed and Butcher [37]. Attempts have been made to determine its reliability and validity in Iran. This questionnaire is the Iranian scale of the tendency to addiction made by Zarghar according to the psychosocial conditions of the Iranian society [38]. The questionnaire has 36 items plus 5 "lie detector" items and a combination of two active readiness and passive readiness for addiction. Active readiness is related to anti-social behavior, craving, positive attitude towards drugs, depression, and sensation seeking while most articles of passive readiness are related to the lack of assertiveness and depression. Zarghar used the two methods to calculate the scale validity [38]. In the criterion validity, Addiction Tendency Questionnaire well distinguished addicted and non-addicted groups from each other. The construct validity of the scale by linking it with a 25 -item list of clinical symptoms scale was calculated as 0.45 , which is significant. Reliability of the scale was calculated as 0.90 using Cronbach's alpha that is in an optimal level. In the present study, Cronbach's alpha coefficient for the important items of the questionnaire was 0.90 . In addition to mentioned tools, in order to investigate the substance use of the subjects, they were asked to answer the question "Did you have the experience of consuming any of cigarettes, tobacco, opium, hashish, glass, alcohol, or other drugs in the last month" with yes or no choices. For scoring this question, score zero was applied in case of the absence of substance use and score one in case that the subject had consumption experience.

\section{Results}

Demographic data indicated that $58.7 \%$ of the subjects were female and $41.3 \%$ were male, $92 \%$ of them were single and $8 \%$ were married. The mean age of the subjects was 21.56 with a standard deviation of $2.52 .32 \%$ of the participants $(31.8 \%$ of females and $32.3 \%$ of males) experienced drug use (cigarettes, tobacco, opium, hashish, glass, or alcohol) in the past month, while $68 \%$ of the subjects (68.2\% of females and $67.7 \%$ of males) had no experience of substance use in the past 
month. Table 1 presents the mean and standard deviation of research variables. According to the data presented in this table, the average score of the subjects' resilience was 55.52 with a standard deviation of 15.33 and the average score of the tendency to addiction in all subjects was 38.33 with a standard deviation of 16.81 . The average score of resilience in females was
59.30 with a standard deviation of 14.72 and the average score of the tendency to addiction in females was 34.44 with a standard deviation of 17.19. In addition, the average score of resilience in males was 50.16 with a standard deviation of 14.61 and the mean score of the tendency to addiction in males was 43.84 with a standard deviation of 14.65.

Table 1 Mean and standard deviation of resilience and tendency to addiction

\begin{tabular}{lcccc}
\hline Variable & \multicolumn{2}{c}{ Tendency to addiction } & \multicolumn{2}{c}{ Resilience } \\
\hline & $\mathrm{M}$ & $\mathrm{SD}$ & $\mathrm{M}$ & $\mathrm{SD}$ \\
\hline Female & 34.44 & 17.19 & 59.30 & 14.72 \\
Male & 43.84 & 14.65 & 50.16 & 14.61 \\
Total & 38.33 & 16.81 & 55.52 & 15.33 \\
\hline
\end{tabular}

Pearson and point-biserial correlation tests were used to examine the relationship between the study variables. Before performing the tests, to verify the normal distribution of sampling, Kolmogorov-Smirnov test, and skewness and kurtosis values were calculated. Although Kolmogorov-Smirnov test results indicated the rejection of the hypothesis of normality in the sampling distribution of resilience $(\mathrm{K}-\mathrm{S}$ test= $630.0, \mathrm{p}<0.006)$ and tendency to addiction (K-S test $=0.060, p<0.012$ ), due to the high volume of sample $(\mathrm{n}=300)$ and the lack of severe deviation in resilience $(\mathrm{Ku}=0.50, \mathrm{Sk}=0.20)$ and tendency to addiction $(\mathrm{Ku}=-0.75, \mathrm{Sk}=-$ 0.04 ) from the normal form (lack of violation of the amount of skewness and kurtosis in the range between +1 to -1 ), the use of tests which requires the normal distribution of sampling was permitted.

The results of the correlation were presented in Table 2. As the correlation matrix of this table shows, there is a significant positive relationship $(\mathrm{r}=0.28, \mathrm{p}<0.01)$ between the tendency to addiction and substance use and there is a significant negative relationship $(\mathrm{r}=-0.44, \mathrm{p}<0.01)$ between the tendency to addiction and resilience. There is a negative relationship $(r=-0.29, p<0.01)$ between male gender and resilience and there is a positive significant relationship $(\mathrm{r}=0.29, \quad \mathrm{p}<0.01)$ between male gender and tendency to addiction.

Table 2 The correlation matrix of research variables

\begin{tabular}{lcccc}
\hline Variable & 1 & 2 & 3 & 4 \\
\hline 1. Substance use & - & - & - & - \\
2. Resilience & -0.08 & - & - & - \\
3. Tendency to addiction & $0.28^{* *}$ & $-0.44^{* *}$ & - & - \\
4. Gender & - & $-0.29^{* *}$ & $0.28^{* *}$ & - \\
\hline$*{ }^{*}<0.01,{ }^{*} \mathrm{p}<0.05$ & & & &
\end{tabular}

After examining the correlation coefficients between variables, structural equation modeling was used to examine the moderating effect of resilience and tendency to addiction on the relationship between gender and substance use. The goodness of fit indices that were obtained to this model showed that chi-square value $(\chi 2=59.57, p=0.001)$ was significant suggesting there is a significant difference between the variance-covariance matrix derived from the data and the expected variance-covariance matrix. Nevertheless, according to that the chi-square value is heavily influenced by sample size, in samples with high volume (over 200), the index is significant in most cases; so, the examination of other model parameters is essential. The examination of the fit parameters in Table 3 shows that the model is fitted well to the data.

Path coefficients of the model are presented 
in Figure 2. As the provided coefficients show, gender has a positive direct effect on the tendency to addiction $(\beta=0.65)$ and it has a negative direct effect on resilience $(\beta=-0.42)$ and substance use $(\beta=-0.82)$. It means that men have reported more tendency to addiction and less resilience and substance use in comparison with women. The direct effect of the tendency to addiction on substance use $(\beta=0.32)$ is positive and the direct effect of resilience on substance use $(\beta=-0.17)$ is negative, indicating that people with more tendency to addiction and less resilience have reported more substance use. The indirect effect of gender on substance use whether by the mediation of tendency to addiction $(\beta=0.21)$ or with the mediation of resilience $(\beta=0.07)$ is positive, which suggests that being a man with an increased tendency to addiction and reduced resilience to addiction leads to substance use. The indirect effect of the tendency to addiction on the substance use through resilience $(\beta=0.05)$ is positive, indicating that the tendency to addiction leads to substance use by reducing the resilience. Therefore, in this model, the role of resilience is determining and male gender and tendency to addiction lead to substance use by reducing the resilience.

Table 3 The fitting indices of the model of research

\begin{tabular}{lcc}
\hline Index & Acceptable value & Earned value \\
\hline Root-mean-square error of approximation (RMSEA) & Is smaller than 0.1 & 0.10 \\
Comparative fit index (CFI) & Is greater than 0.9 & 0.92 \\
Normed fit index (NFI) & Is greater than 0.9 & 0.90 \\
The Goodness of fit index (GFI) & Is equal to or greater than 0.9 & 0.96 \\
The Adjusted goodness of fit index (AGFI) & Is equal to or greater than 0.9 & 0.89 \\
\hline
\end{tabular}

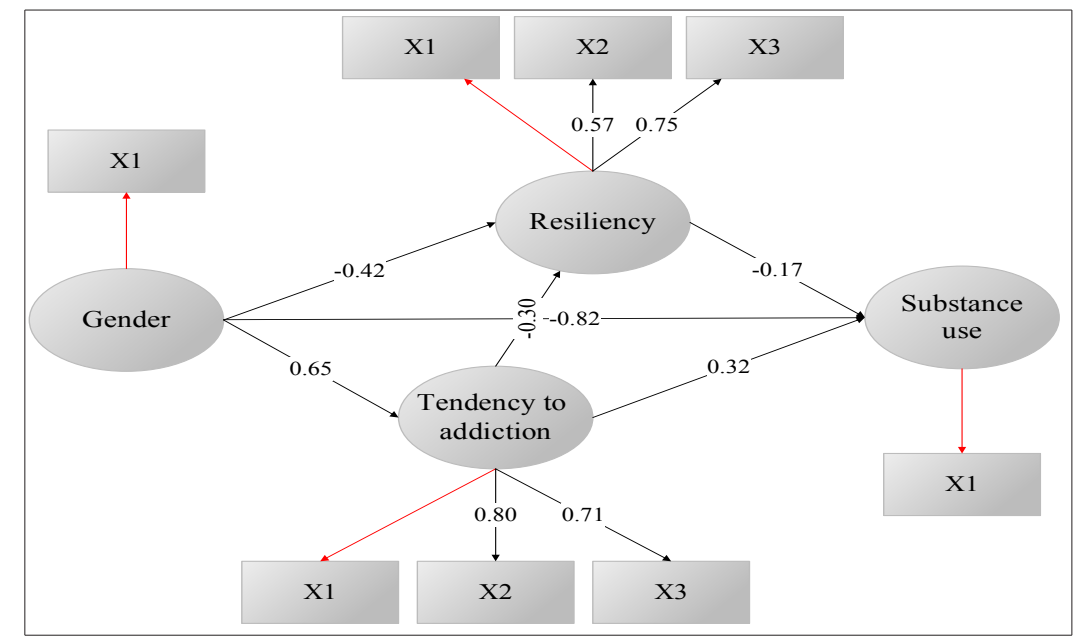

Figure 2 Structural equation modeling and path coefficients

\section{Discussion}

As expected, there was a significant positive relationship between the tendency to addiction and substance use, there was a negative relationship between resilience and tendency to addiction, and there was a significant relationship between gender and tendency to addiction and resilience. The designed model to examine the mediating role of resilience and tendency to addiction regarding the effect of gender on substance use adequately fitted the data; particularly it emphasized the role of resilience in relation to the effect of gender and tendency to addiction in substance use. This finding is consistent with the findings of several studies that emphasized the role and importance of resilience in the prevention of drug use and addiction. For example, a study showed that people with high resilience have 
better health, higher self-esteem, and more social support and are less prone to substance use [30]. Another study showed that high resilience is associated with fewer cigarettes consumption and less dependent on nicotine [31]. Other study found that a higher grade of resilience is associated with more days without smoking in the smoking cessation program [32]. A study with a large sample of adults in the city also have shown that childhood abuse is associated with alcohol and illegal drug abuse in people with less resilience, but it had no relation with the drug abuse in people with high resilience [19].

In conducted research in Iran, a study showed that the amount of anxiety, depression, and stress in subjects with risk of substance abuse is high and their resilience is low [39]. Another study showed that there is a significant positive relationship between academic burnout, perceived stress, and low resilience and tendency to addiction and these factors overall explained $20 \%$ of the variance of tendency to addiction that among these factors, only the effect of resilience and ability to cope with tendency to addiction was significant [16]. Other study concluded that there is a negative relationship between the resilience and tendency to substance use and resilience along with attachment styles can predict the tendency to substance use among students [33]. Another study also found that becoming a member of the addicts and non-addicts groups could be predicted by the elements of personality, identity style, spirituality, and resilience [34]. Resilience as a process is considered as the ability or outcome of successful adaptation to the environment, despite the risk and threats, and it enables persons to acquire skills necessary for leaving behind problems; even in very adverse and hard conditions, they cope with the challenges of the life and the stressful conditions [17] and it is defined as a method to measure a person's ability to cope with stressors and factors that threaten psychological health [35]. In other words, resilience is a psychological concept explaining how people deal with unexpected situations.
However, resilience not only is the increase of tolerance and adjustment in dealing with the problem but also, more importantly, is related to maintaining of mental health and even improving it. Resilience enables people to face difficulties and hardships, without being damaged and even use these opportunities for prosperity and growth of their character.

The term resilience as a component of personality in the late twentieth century was introduced into the psychological research based on excellent research in the field of control and direct influence on cognitive processes [20]. Initial theories about resilience emphasized the traits associated with positive outcomes in the face of adversity and tribulations of the life. These studies further showed that outer protective factors such as schools, efficient and supportive relationships with adults are also helpful in increasing resilience [21].

In earlier studies, it was thought that resilience was the feature of wonderful people. However, recent research has shown that resilience, despite gender differences, is not the monopoly of great people and it has been observed in different people and at different levels of development, including childhood, adolescence, and adulthood [22]. The results indicate that high levels of resilience help a person to use emotions and positive affections for leaving behind bad experiences and returning to good condition by increasing the levels of positive emotions and strengthening self-esteem and overcoming negative experiences [25].

Many researchers have reported a significant negative relationship between resilience and psychological problems [26]. They suggest that these structures can be used as a mediator between mental health and many other variables and by promoting resilience, a person can gain resistance against stress and anxiety and overcome the factors that caused many psychological problems [27]. Nevertheless, the interesting finding of this study is that while men reported more readiness for addiction, in practice, women 
have reported more substance use. Therefore, it can be concluded that although the tendency to addiction and substance use was positively correlated with each other, the addiction tendency questionnaire necessarily does not anticipate soft drugs abuse such as tobacco and girls with a lower tendency to addiction have reported more soft drugs abuse.

These findings can also be a warning to the occurrence of addiction in girls. However, before addiction was considered a male problem, a very small percentage of women had this problem. But, in recent years, we can see a rise in drug addiction among women and regarding the fact that soft drugs such as cigarettes are the gateway for heavier drugs abuse and engaging in addiction, it is possible that in the coming years we will see the more prevalence of addiction among women that highlights the necessity of planning in this regard.

This study had limitations that reduced our ability to generalize the findings. One of these limitations is the retrospective nature of the study and doing it in a student community. The prospective-design studies and research on other samples and comparing addicts and non-addicts can more clearly express the role of resilience in the context of the relationship between gender and substance use.

\section{Conclusion}

According to the results of this study and the role of resilience in relation to the effects of gender and tendency to addiction in substance use, we can say that the moderating role of resilience in the relationship between the tendency to addiction and substance use can be due to an increase in mental health due to resilience. Given that this feature can be increased by training, we can increase the mental health of individuals prone to addiction by training the components of resilience and therefore, we can prevent the tendency to addiction and substance abuse in them. Nevertheless, in this context, it should be considered that due to the different patterns of the tendency to addiction and substance use among women and men and different coping strategies in dealing with problems, the consideration of gender in designing of interventions may be necessary.

\section{Acknowledgments}

Thanks to all those who helped us with this study.

\section{Contribution}

Study design: $\mathrm{HJ}, \mathrm{MH}$

Data collection and analysis: $\mathrm{HJ}, \mathrm{MH}, \mathrm{AN}$

Manuscript preparation: HJ, AN

\section{Conflicts of Interest}

"The authors declare that they have no competing interests."

\section{Funding}

The author (s) received no financial support for the research, authorship and/or publication of this article.

\section{References}

1- Melchior M, Chastang JF, Goldberg P, Fombonne E. High prevalence rates of tobacco, alcohol and drug use in adolescents and young adults in France: results from the GAZEL Youth study. Addict Behav2008; 33(1): 122-33.

2- Newcomb MD, Bentler PM. Consequence of adolescent drug use: impact on the lives of young adults. Thousand Oaks, California, US: Sage publications; 1988.

3- Sutin AR, Evans MK, Zonderman AB. Personality traits and illicit substances: the moderating role of poverty. Drug Alcohol Depend2013; 131(3): 247-51.

4- World Health Organization. The world health report 2002, reducing risks, promoting healthy life. World Health Organization; 2002.

5- Terracciano A, Löckenhoff CE, Crum RM, Bienvenu OJ, Costa PT. Five-factor model personality profiles of drug users. BMC Psychiatry2008; 8(1): 22-32.

6- Becker JB, Koob GF. Sex differences in animal models: focus on addiction. Pharmacological Reviews2016; 68(2): 242-63.

7- Kuhn C. Emergence of sex differences in the development of substance use and abuse during adolescence. Pharmacol Ther2015; 153: 55-78.

8- Painter D, Tice P. Results from the 2013 national survey on drug use and health: summary of national findings. Rockville: Substance abuse and mental health services administration; 2013. 
9- Holdcraft LC, Iacono WG. Cohort effects on gender differences in alcohol dependence. Addiction 2002; 97(8): 1025-36.

10- Simons-Morton BG, Farhat T, ter Bogt TF, et al. Gender specific trends in alcohol use: cross-cultural comparisons from 1998 to 2006 in 24 countries and regions. Int J Public Health2009; 54(2): 199-208.

11- Kerr WC, Greenfield TK, Bond J, Ye Y, Rehm J. Age-period-cohort modelling of alcohol volume and heavy drinking days in the US National Alcohol Surveys: divergence in younger and older adult trends. Addiction2009; 104(1): 27-37.

12-Keyes KM, Grant BF, Hasin DS. Evidence for a closing gender gap in alcohol use, abuse, and dependence in the United States population. Drug Alcohol Depend2008; 93(1-2): 21-9.

13- Bingham CR, Shope JT, Tang X. Drinking behavior from high school to young adulthood: differences by college education. Alcohol Clin Exp Res2005; 29(12): 2170-80

14- Bobzean SA, DeNobrega AK, Perrotti LI. Sex differences in the neurobiology of drug addiction. Exp Neurol2014; 259: 64-74.

15- Moran-Santa Maria MM, Flanagan J, Brady K. Ovarian hormones and drug abuse. Curr Psychiatry Rep2014; 16(11): 511.

16- Salmabadi M, Salimi Bajestani H, Khayami Abiz $\mathrm{H}$, javan $\mathrm{R}$. The role of academic burnout, resilience, and perceived stress in predicting students' addiction Potential. Journal of Research on Addiction2015; 9(33): 21-39.

17- Clauss- Ehlers CS. Sociocultural factors, resilience, and coping support for a culturally sensitive measure of resilience. J Appl Dev Psychol2008; 29(3): 197-212.

18- Asnaani A, Alpert E, McLean CP, Foa EB. Resilient but addicted: The impact of resilience on the relationship between smoking withdrawal and PTSD. $J$ Psychiatr Res2015; 65: 146-53.

19- Wingo AP, Ressler KJ, Bradley B. Resilience characteristics mitigate tendency for harmful alcohol and illicit drug use in adults with a history of childhood abuse: a cross-sectional study of 2024 inner-city men and women. J Psychiatr Res2014; 51: 93-9.

20- Lemay R, Ghazal H. Resilience and positive psychology: finding hope. Child and Family2001; 5(1): 10-21.

21- Luthar SS, Cicchetti D, Becker B. The construct of resilience: a critical evaluation and guidelines for future work. Child Dev2000; 71(3): 543-62.

22- Campbell-Sills L, Cohan SL, Stein MB. Relationship of resilience to personality, coping, and psychiatric symptoms in young adults. Behav Res Ther2006; 44(4): 585-99.

23- Erdogan E, Ozdogan O, Erdogan M. University students' resilience level: The effect of gender and faculty.
Procedia Soc Behav Sci2015; 186(13): 1262-7.

24- Masood A, Masud Y, Mazahir S. Gender differences in resilience and psychological distress of patients with burns. Burns2016; 42(2): 300-6.

25- Maddi SR, Khoshaba DM, Persico M, Lu J, Harvey $\mathrm{R}$, Bleecker F. The personality construct of hardiness: relationships with comprehensive tests of personality and psychopathology. J Res Pers2002; 36(1): 72-85.

26- Hu T, Zhang D, Wang J. A meta-analysis of the trait resilience and mental health. Pers Individ Dif2015; 76: 18-27.

27- Besharat MA, Salehi M, Shahmohammadi K, Nadali H, Zebardast O. Relations of resilience and hardiness with sport achievement and menatal health in a sample of athletes. Contemporary Psychology2009; 3(2): 38-49.

28- Friborg O, Barlaug D, Martinussen M, Rosenvinge $\mathrm{JH}$, Hjemdal O. Resilience in relation to personality and intelligence. Int J Methods Psychiatr Res2005; 14(1): 29-42.

29- Vincent EC. Gender differences in protective factors associated with educational, emotional and dual domain resilience. Indiana: Indiana university; 2007.

30- Buckner JC, Mezzacappa E, Beardslee WR. Characteristics of resilient youths living in poverty: The role of self-regulatory processes. DevPsychopathol2003; 15(1): 139-62.

31- Goldstein AL, Faulkner B, Wekerle C. The relationship among internal resilience, smoking, alcohol use, and depression symptoms in emerging adults transitioning out of child welfare. Child Abuse Negl2013; 37(1): 22-32.

32- Pergadia ML. Personal resources and smoking cessation: promoting assets and preventing liabilities. [dissertation]. Chicago: Finch university of health sciences 2002.

33- Bahadori-Khosroshahi J, Hashemi-Nosratabadi T, Bayrami M. Relationship between attachment styles and resiliency with tendency to drug use. Journal of Research on Addiction2010; 14(4): 17-30.

34- Hosseini-Almadani SA, Karimi Y, Bahrami H, Moazedian A. Predicting membership in addict \& nonaddict groups according to spirituality, personality traits, identity styles, and resiliency. Journal of Medical Sciences University of Rafsanjan2013; 12: 57-70.

35- Conner KM, Davidson JR. Development of a new resilience scale: the connor-avidson resilience scale (CD-RISC). Depress Anxiety2003; 18(2): 76-82.

36- Ahmadi R, Sharifi Daramadi P. The effectiveness of resilience training on mental health of people with substance dependence at the Touska center of Tehran. Journal of Clinical Psychology Studies2014; 16: 1-17.

37- Weed NC, Butcher JN, McKenna T, Ben-Porath YS. New measures for assessing alcohol and other 
drug problems with MMPI-2, The APS and AAS. $J$ Pers Assess 1992; 58(2): 389-404.

38- Zarghar Y, Najjarian B, Nami AZ. Investigate the relationship between personality characteristics (sensation seeking, self-expression, hardiness), religious attitude and marital satisfaction with preparation for addiction.
Education and Psychology Journal of Shahid Chamran University 2008; 3: 99-120.

39- Mohammadi A, Aghajani M, Zehtabvar G. Addiction and its relation with resilience and emotional components.Iranian Journal of Psychiatryand Clinical Psychology2011; 2: 136-42.

Copyright $\odot 2016$ ASP Ins. This open-access article is published under the terms of the Creative Commons Attribution-NonCommercial 4.0 International License which permits Share (copy and redistribute the material in any medium or format) and Adapt (remix, transform, and build upon the material) under the Attribution-NonCommercial terms. 